\title{
Genetic diversity of Bemisia tabaci (Genn.) Populations in Brazil revealed by RAPD markers
}

\author{
L.H.C. Lima, L. Campos, M.C. Moretzsohn, D. Návia and M.R.V. de Oliveira \\ Embrapa Recursos Genéticos e Biotecnologia, Brasília, DF, Brazil.
}

\begin{abstract}
Bemisia tabaci (Genn.) was considered a secondary pest in Brazil until 1990, despite being an efficient geminivirus vector in beans and soybean. In 1991, a new biotype, known as B. tabaci B biotype (=B. argentifolii) was detected attacking weed plants and causing phytotoxic problems in Cucurbitaceae. Nowadays, B. tabaci is considered one of the most damaging whitefly pests in agricultural systems worldwide that transmits more than 60 different plant viruses. Little is known about the genetic variability of these populations in Brazil. Knowledge of the genetic variation within whitefly populations is necessary for their efficient control and management. The objectives of the present study were to use RAPD markers (1) to estimate the genetic diversity of $B$. tabaci populations, (2) to study the genetic relationships among $B$. tabaci biotypes and two other whitefly species and (3) to discriminate between $B$. tabaci biotypes. A sample of 109 B. tabaci female individuals obtained from 12 populations in Brazil were analyzed and compared to the A biotype from Arizona (USA) and B biotype from California (USA) and Paraguay. Trialeurodes vaporariorum and Aleurodicus cocois samples were also included. A total of 72 markers were generated by five RAPD primers and used in the analysis. All primers produced RAPD patterns that clearly distinguished the Bemisia biotypes and the two other whitefly species. Results also showed that populations of the B biotype have considerable genetic variability. An average Jaccard similarity of 0.73 was observed among the B biotype individuals analyzed. Cluster analysis demonstrated that, in general, Brazilian biotype B individuals are scattered independently in the localities where samples were collected. Nevertheless, some clusters were evident, joining individuals according to the host plants. AMOVA showed that most of the total genetic variation is found within populations (56.70\%), but a significant portion of the variation is found between crops $(22.73 \%)$. The present study showed that the $B$ biotype is disseminated throughout the sampled areas, infesting several host plants and predominates over the A biotype.
\end{abstract}

Key words: whitefly, molecular markers, UPGMA, AMOVA.

Received: March 5, 2002; accepted: July 15, 2002.

\section{Introduction}

Bemisia tabaci (Genn.) (Hemiptera: Aleyrodidae), known as the California strain, cotton strain, A-strain and A biotype (Perring, 1995), has been detected in Brazil since 1928 (Bondar, 1929). Before 1990, this species was considered an occasional pest and a vector of phytovirus in beans, soybeans and tomato (Costa et al., 1977). The Brazilian $B$. tabaci population also known as the $B$. tabaci biotype BR (Lima et al., 2000) occurs on several native and cultivated host plants and is thought to be widely distributed in the country. This biotype may represent an indigenous biotype of $B$. tabaci as it does not feed on cassava, contrary to A biotype and is a vector of only three geminiviruses: the

Send correspondence to Luzia Helena Corrêa Lima. Embrapa Recursos Genéticos e Biotecnologia, Prédio do Controle Biológico, Caixa Postal 02372, 70770-900 Brasilia, DF, Brazil. E-mail: luzia@cenargen.embrapa.br. bean golden mosaic virus, the bean dwarf mosaic virus and the tomato golden mosaic virus.

In the last three decades, a new biotype has colonized the Americas, causing heavy losses in different agroecosystems. This new biotype was first detected in poinsettia in Florida (USA) and received the common names of Florida strain or poinsettia strain. It has also been known as $\mathrm{B}$-strain, $\mathrm{B}$ biotype or type $\mathrm{B}$, to distinguish it from the indigenous species presented in the United States (A biotype). Results of allozyme and RAPD analyses, insecticide applications, and mating studies have led some authors to conclude that A and B biotypes differ genetically and should be considered as separate species (Wool et al., 1993; Perring et al., 1993; Bellows et al., 1994). The name, Bemisia argentifolii (Bellows et al., 1994) and the common name of silverleaf whitefly (Perring et al., 1993) have been suggested for this biotype. This distinction is not widely accepted (De Barro, 1995; Williams et al., 1996) and the taxonomic classification of Bemisia is still controversial. In 
Australia, the presence of hybrids derived from crosses between the silverleaf whitefly and the indigenous whitefly in cotton crops suggests that $B$. tabaci may be a species-complex undergoing evolutionary change (Drost et al., 1998; Franzmann et al., 2000).

The B biotype is biologically distinct from the A biotype (Costa et al., 1993). The B biotype is more fecund than the A, produces greater amounts of honeydew, has a broader host plant range, exhibits significantly higher levels of insecticide resistance and induces several different phytotoxic disorders in certain plant hosts (Costa and Brown, 1991; Liu et al., 1992; Anthony et al., 1995). However, morphological markers cannot reliably distinguish these two biotypes.

In Brazil, B. tabaci biotype B was introduced in the early 1990s, probably through the international trade of ornamental plants (Lourenção and Nagai, 1994). It was first detected in the state of São Paulo. In the last three years it has spread to all regions of the country and has been estimated to cause losses greater than US\$ 2.0 billion dollars (Oliveira and Faria, 2000). The main crops attacked are melon, watermelon, cotton, beans, soybeans, okra, tomato, and cabbage. Insecticides have been used weekly on crops in some areas to control the insect populations. The ability to colonize over 600 different plant species and vector over 60 different plant viruses is cause for great concern within agricultural regions of the world (Secker et al., 1998).

Knowledge of the genetic variation within whitefly populations is necessary for their efficient control and management. Random Amplified Polymorphic DNA (RAPD) markers provide a powerful tool for the investigation of genetic variation. RAPD does not require prior genomic information, and is simpler, less costly, and less labor intensive than other DNA marker methodologies. In Bemisia, RAPD markers have been used for analysis of genetic variation (Gawel and Bartlett, 1993; De Barro and Driver, 1997; Guirao et al., 1997; Moya et al., 2001), for taxonomic studies (Perring et al., 1993), biotype identification and geographical distribution (Lima et al., 2000; Martinez et al., 2000).

In the past four years, whitefly samples have been collected on native and cultivated plants from several geographical locations in Brazil (Lima et al., 2000). No assessed crop was found to be exclusively attacked by biotype BR of B. tabaci. Rather, the survey has shown the dominance and broad host range of the B biotype in this country.

In spite of this, little is known about the genetic variability of the Brazilian populations. The main objectives of the present study were to use RAPD markers to (1) estimate the genetic diversity of $B$. tabaci populations, (2) study the genetic relationships among $B$. tabaci biotypes and two other whitefly species, and (3) discriminate between $B$. tabaci biotypes.

\section{Material and Methods}

\section{Insect populations}

Adult whiteflies were collected from host plants using a hand-held aspirator and preserved immediately in $100 \%$ ethanol. Samples were maintained in a refrigerator, at $4{ }^{\circ} \mathrm{C}$, until DNA extraction (maximum period of 15 days). A total of $109 \mathrm{~B}$. tabaci biotype B individuals were collected in 12 localities in seven Brazilian States (Figure 1) and on seven distinct host plants (Table I). All strains used in this study were first identified as B. tabaci, based on the morphology of the pupal stage and RAPD patterns. We also included an indigenous biotype from Brazil (B. tabaci biotype BR), biotype A from Arizona (USA), biotype B from California (USA) and Paraguay, and two other whitefly species: Trialeurodes vaporariorum (Westwood) and Aleurodicus cocois (Curtis).

\section{DNA extraction}

A single step DNA extraction method was used according to a protocol described originally by Aljanabi et al. (1998) with some modifications. Each individual female whitefly was homogenized in a $1.5 \mathrm{~mL}$ microcentrifuge tube with $60 \mu \mathrm{L}$ of lysis buffer $(10 \mathrm{mM}$ Tris- $\mathrm{HCl} \mathrm{pH} 8.0$, $1 \mathrm{mM}$ EDTA, $0.30 \%$ Triton $\mathrm{X}-100,60 \mu \mathrm{g} / \mathrm{mL}$ proteinase $\mathrm{K})$. The homogenate was then incubated at $65{ }^{\circ} \mathrm{C}$ for $15 \mathrm{~min}$. Samples were boiled for six minutes to inactivate the proteinase $\mathrm{K}$ and stored at $-20^{\circ} \mathrm{C}$.

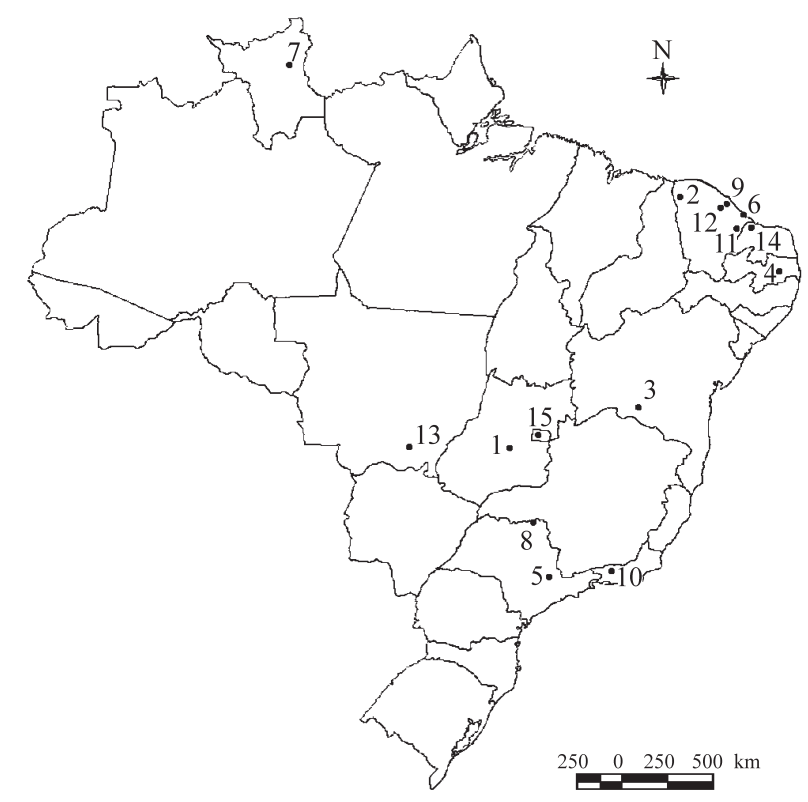

Figure 1 - Map of Brazil indicating the localities where Bemisia individuals were collected. Map numbers correspond to the populations indicated in Table I. 
Table I - Host plants, sites where whitefly populations were collected, $B$. tabaci biotypes (or insect species) population codes used in the analyses and number of individuals analyzed per population. Numbers following the localities correspond to the numbers indicated in the map (Figure 1).

\begin{tabular}{|c|c|c|c|c|}
\hline Host plant & Locality - State & Biotype or species & Population code & Number of individuals \\
\hline \multirow[t]{2}{*}{ Cabbage } & Goianira, Goiás (GO) - 1 & $\mathrm{~B}$ & CBGO & 10 \\
\hline & Tianguá, Ceará (CE) - 2 & $\mathrm{~B}$ & $\mathrm{CBCE}$ & 10 \\
\hline \multirow[t]{2}{*}{ Cotton } & Guanambi, Bahia (BA) - 3 & $\mathrm{~B}$ & CTBA & 10 \\
\hline & Campina Grande, Paraíba (PB) - 4 & $\mathrm{~B}$ & СТРB & 10 \\
\hline Grape & Campinas, São Paulo (SP) - 5 & $\mathrm{~B}$ & GRSP & 4 \\
\hline Melon & Boa Vista, Roraima (RR) - 7 & $\mathrm{~B}$ & MERR & 10 \\
\hline Melon & California - USA & $\mathrm{B}$ & USAB & 5 \\
\hline \multirow[t]{2}{*}{ Soybean } & Miguelópolis, São Paulo (SP) - 8 & $\mathrm{~B}$ & SBSP & 10 \\
\hline & Guaiuba, Ceará (CE) - 9 & $\mathrm{~B}$ & SBCE & 10 \\
\hline \multirow[t]{2}{*}{ Squash } & Vassouras, Rio de Janeiro (RJ) - 10 & $\mathrm{~B}$ & SQRJ & 10 \\
\hline & Tabuleiro do Norte, Ceará (CE) - 11 & $\mathrm{~B}$ & SQCE & 10 \\
\hline Tomato & Pacoti, Ceará (CE) - 12 & $\mathrm{~B}$ & TOCE & 5 \\
\hline Melon & Arizona - USA & A & USAA & 5 \\
\hline Weed & Rondonópolis, Mato Grosso (MT) - 13 & $\mathrm{BR}$ & Weed & 5 \\
\hline Cashew & Mossoró, Rio Grande do Norte (RN) - 14 & Aleurodicus cocois & AleRN & 5 \\
\hline Melon & Brasília, Distrito Federal (DF) - 15 & Trialeurodes vaporariorum & TriDF & 5 \\
\hline
\end{tabular}

\section{RAPD assays}

RAPD analyses were carried out according to Aljanabi et al. (1998) with some modifications. Amplification reactions were performed in a $30 \mu \mathrm{L}$ reaction mix, containing a final concentration of $6.0 \mathrm{mM}$ Tris- $\mathrm{HCl} \mathrm{pH} 8.8$, $0.2 \mu \mathrm{M}$ dNTPs, $0.4 \mu \mathrm{M}$ of 10-base primer (Operon Technologies Inc.), $2.5 \mathrm{U}$ of Taq DNA polymerase and 10-15 ng DNA (usually $4 \mu \mathrm{L}$ ), overlaid with a drop of mineral oil to prevent evaporation. Amplifications were performed in a PTC-100 thermal cycler (MJ Research). Reaction products were then analyzed by $1.5 \%$ agarose gel electrophoresis. Gels were photographed under UV following ethidium bromide staining. A negative control, without DNA, was included in all reactions. Some standard procedures were adopted to ensure the reproducibility of the results: the use of the same termocycler, Taq DNA polymerase from the same producer, the same amount of all the mix components in all the experiments; the inclusion of only strong bands in the analysis and the inclusion of standard DNA samples.

\section{Data analysis}

PCR amplification products of the 139 samples were scored as presence (1) or absence (0) of bands. The data matrix was used to calculate Jaccard's similarity coefficient (Sneath and Sokal, 1973) which does not consider the joint absence of a marker as an indication of similarity. A dendrogram was constructed using the unweighted pair-group method analysis (UPGMA). The frequencies of the RAPD fragments were estimated for each of the 15 Bemisia popu- lations and for the two other whitefly species. The resulting matrix was used to calculate Manhattan distances between all pairs of populations or species. These analyses were performed using NTSYS-pc software, version 2.0 (Rohlf, 1993).

Analysis of Molecular Variance (AMOVA) (Excoffier et al., 1992) was used to analyze the partition of the total genetic variation between the sampled crops, between and within Brazilian biotype B populations. A total of 41 RAPD markers (with less than 5\% of missing data) was used for this analysis, performed using Arlequin software, version 1.1 (Schneider et al., 1997).

\section{Results and Discussion}

Five of the twenty-seven primers screened produced clear bands on the RAPD amplifications and were used for analysis. These primers (OPA-02, OPA-04, OPA-05, OPA-10, and OPA-13) amplified a total of 72 markers. The total number of clear bands obtained from each primer ranged from 4 (OPA-02) to 20 (OPA-10), with an average of 14.4 bands per primer. Forty bands (55.5\%) out of 72 were polymorphic for $\mathrm{B}$ biotype populations ( 8.0 polymorphic markers per primer). The size of amplification products ranged from $300 \mathrm{bp}$ to $1500 \mathrm{bp}$. An example of RAPD amplification patterns is shown in Figure 2. All primers produced identical RAPD patterns for the selected bands in the primer screening step and in the final analysis, and in the several replicated experiments that were done.

Genetic relationships between populations are shown in Table II. Considering only the $\mathrm{B}$ biotype populations, the average genetic distances were 0.201 . The smallest average 


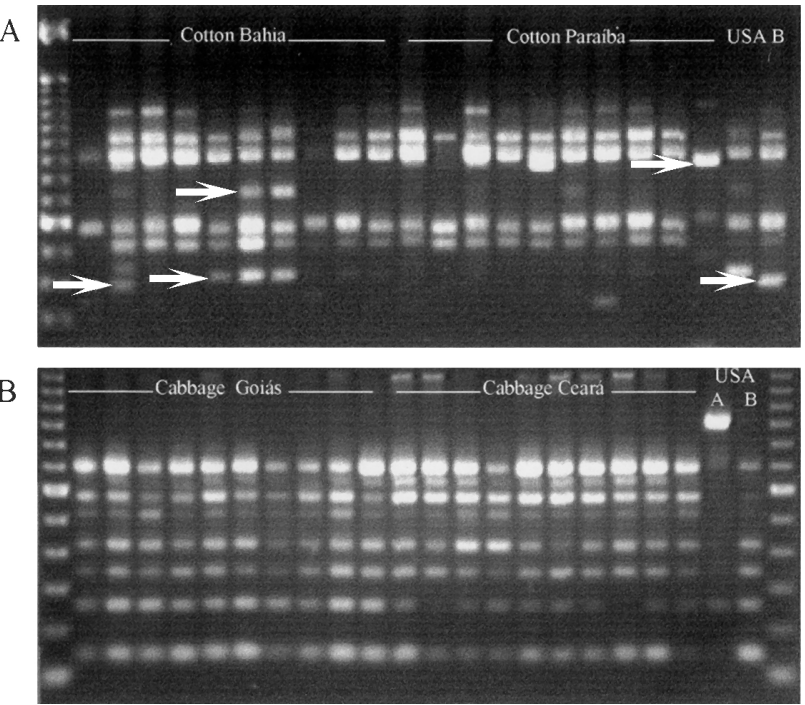

Figure 2 - Example of RAPD patterns generated by primers OPA-05 (A) and OPA-13 (B). Arrows indicate the polymorphic fragments used in the analysis. Lanes 1 in panel A and lanes 1 and 24 in panel B are 100 bp DNA ladder.

distance (0.08) was between populations TOPY (tomato from Paraguay) and GRSP (grape from Campinas, São Paulo) while the highest $(0.31)$ was between TOCE (tomato from Pacoti, Ceará) and SBSP (soybean from Miguelópolis, São Paulo). In general, higher distances were observed between biotype B populations and the other two biotypes (A and $\mathrm{BR}$ ) and species (T. vaporariorum and $A$. cocois), with values ranging from 0.29 to 0.57 .

An UPGMA dendrogram based on Jaccard's similarity coefficient was constructed for the 139 samples analyzed (Figure 3). Four major groups were evident. The first group contained all populations of $B$. tabaci biotype $\mathrm{B}$ from different localities. This group is basically divided into four subgroups. The first subgroup consists of individuals collected on soybean from Ceará, the second includes cabbage, cotton, and squash from different localities and soybean from São Paulo, the third group consists of melon from Ceará and Roraima States, and the fourth subgroup includes grape and tomato populations and B biotype samples from the USA. The second major group included populations of B. tabaci biotype A and BR collected from populations in Arizona, the USA and Brazil, respectively. The third and the fourth major groups contain the two other whitefly species: $T$. vaporariorum and A. cocois.

Cluster analysis showed that, in general, biotype B individuals are scattered independently in the localities where the samples were collected, especially samples from the CTBA (cotton, Bahia), CTPB (cotton, Paraíba), and SBSP (soybean, São Paulo) populations. Nevertheless, some clusters were evident, joining individuals according to the host plants. This result suggests that a differentiation of populations has already occurred, mainly according to the host plant, instead of the geographical region where populations are localized. No grouping of samples collected on different crops in the same State was obtained. Individuals collected on three different crops (tomato, melon, and squash) and from the same state (Ceará), for example, did not cluster according to the locality, but to the crop (Figure 3). But individuals collected in two very distant States (Ceará and Roraima) (Figure 1), but on the same crop (melon), were joined in the dendrogram. Similar results were obtained for populations collected on cotton crops in Paraíba and Bahia States and on squash from Ceará and Rio de Janeiro. Results of the AMOVA partitioning of genetic variation of $B$. tabaci populations (Table III) corroborated these findings, by showing that a considerable proportion of the total genetic variation $(22.73 \%)$ was found between crops $(\mathrm{p}<0.00293)$. AMOVA also showed that $20.56 \%$ $(\mathrm{p}<0.00001)$ of the total genetic variation was found between populations and $56.70 \%$, within populations. These results indicated that some differentiation of Brazilian B biotype populations has occurred, despite their recent introduction to Brazil. The cluster analyses of the B biotype populations showed the heterogeneous set of groups and

Table II - Manhatan's distance matrix between B. tabaci populations and two other whitefly species. Population codes are listed in Table I.

\begin{tabular}{|c|c|c|c|c|c|c|c|c|c|c|c|c|c|c|c|c|c|}
\hline & CBGO & CBCE & CTBA & СТPB & SBSP & SBCE & MECE & MERR & SQRJ & SQCE & GRSP & TOPY & USAA & USAB & TOCE & Weed & TriDF \\
\hline CBCE & 0.140 & & & & & & & & & & & & & & & & \\
\hline CTBA & 0.120 & 0.120 & & & & & & & & & & & & & & & \\
\hline СТРВ & 0.160 & 0.150 & 0.100 & & & & & & & & & & & & & & \\
\hline SBSP & 0.120 & 0.130 & 0.150 & 0.120 & & & & & & & & & & & & & \\
\hline SBCE & 0.170 & 0.180 & 0.180 & 0.220 & 0.190 & & & & & & & & & & & & \\
\hline MECE & 0.240 & 0.220 & 0.230 & 0.210 & 0.230 & 0.260 & & & & & & & & & & & \\
\hline MERR & 0.230 & 0.210 & 0.200 & 0.190 & 0.220 & 0.240 & 0.110 & & & & & & & & & & \\
\hline SQRJ & 0.160 & 0.160 & 0.180 & 0.170 & 0.140 & 0.200 & 0.200 & 0.200 & & & & & & & & & \\
\hline SQCE & 0.150 & 0.130 & 0.170 & 0.150 & 0.100 & 0.220 & 0.240 & 0.230 & 0.140 & & & & & & & & \\
\hline GRSP & 0.250 & 0.170 & 0.220 & 0.220 & 0.240 & 0.210 & 0.200 & 0.200 & 0.180 & 0.260 & & & & & & & \\
\hline TOPY & 0.260 & 0.210 & 0.240 & 0.240 & 0.260 & 0.240 & 0.210 & 0.200 & 0.230 & 0.270 & 0.080 & & & & & & \\
\hline USAA & 0.520 & 0.520 & 0.540 & 0.530 & 0.570 & 0.520 & 0.490 & 0.460 & 0.520 & 0.560 & 0.430 & 0.440 & & & & & \\
\hline USAB & 0.270 & 0.210 & 0.240 & 0.250 & 0.280 & 0.270 & 0.240 & 0.210 & 0.250 & 0.290 & 0.120 & 0.090 & 0.420 & & & & \\
\hline TOCE & 0.280 & 0.220 & 0.240 & 0.270 & 0.310 & 0.290 & 0.250 & 0.220 & 0.250 & 0.290 & 0.110 & 0.130 & 0.400 & 0.080 & & & \\
\hline Weed & 0.480 & 0.490 & 0.520 & 0.520 & 0.510 & 0.470 & 0.510 & 0.460 & 0.510 & 0.530 & 0.390 & 0.390 & 0.150 & 0.380 & 0.380 & & \\
\hline TriDF & 0.450 & 0.430 & 0.450 & 0.490 & 0.480 & 0.410 & 0.480 & 0.450 & 0.450 & 0.510 & 0.330 & 0.360 & 0.290 & 0.300 & 0.290 & 0.220 & \\
\hline AleRN & 0.500 & 0.480 & 0.500 & 0.510 & 0.530 & 0.440 & 0.500 & 0.460 & 0.510 & 0.530 & 0.370 & 0.410 & 0.310 & 0.390 & 0.380 & 0.290 & 0.280 \\
\hline
\end{tabular}




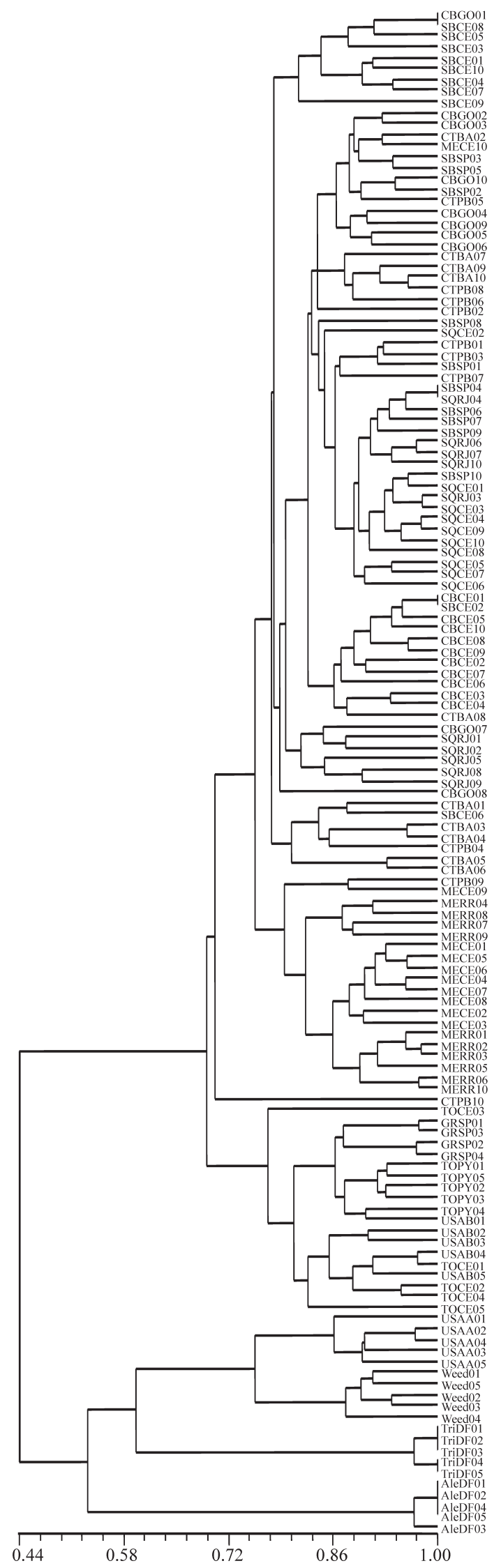

Figure 3 - Dendrogram for the 139 whitefly samples, generated by UPGMA. Population codes are listed in Table I. sub-groups, probably due to differences between several nutritional and behavioral factors. The differentiation observed could also be explained by the introduction of $\mathrm{B}$ biotype populations in Brazil from several rather than a single founder population (Lourenção and Nagai, 1994), by the massive and crop-specific insecticide applications in these populations that could have affected the allele frequencies in different crops or by possible crossings between biotype $\mathrm{B}$ individuals and indigenous biotype individuals.

Genetic variation was detected in all the populations analyzed. Considering only B biotype populations, an average Jaccard similarity of 0.73 was observed between all individuals analyzed. Moreover, UPGMA showed the clustering of individuals by host crops instead of geographical region. These results suggest that management methods established for a host crop in one region would probably function for the same crop in other regions.

Individuals were randomly collected from 10 different populations in Brazil and morphologically identified as Bemisia sp. Samples of A and B biotypes from California (A) and Arizona (B) were included in the analysis as standards. RAPD analysis showed that the great majority of the populations analyzed were the $\mathrm{B}$ biotype instead of the $\mathrm{A}$ or BR biotypes and that the $\mathrm{B}$ biotype is disseminated throughout the sampled areas, even in localities or host plants, such as soybeans and cotton, where the indigenous biotype predominated previously (Lima et al., 2000). Effective monitoring of the spread of $B$. tabaci in Brazil and the ability to reliably distinguish non-B biotypes from the more important $\mathrm{B}$ biotype of this pest will assist in the forecasting of potential losses and improve the prospects for adoption of appropriate management strategies.

A surprising result produced by the cluster analysis (Figure 3) was the grouping of $T$. vaporariorum and $A$. coccois populations with $B$. tabaci biotypes A and BR. This indicates that these two whiteflies, from other genera, are more closely related to $B$. tabaci biotypes A and BR than to biotype $B$. All primers used in this study produced RAPD patterns that clearly distinguished biotypes A (USA) or BR (Brazil) from biotype B or any other distinct whitefly species analyzed. Some of these primers are routinely used to differentiate A and B biotypes (Lima et al., 2000). This fact may have lead to an overestimation of the genetic distances between the two biotypes. In spite of this, genetic distances between populations of A and B biotypes are considerably higher than distances between B biotype populations. These results give support to the preliminary studies based on allozymes (Perring et al., 1992; Bellows et al., 1994), RAPD, crossing experiments and mating behavior studies (Perring et al., 1993) that had led the authors to conclude that B. tabaci biotypes A and B could be different species. Although our data are insufficient to support the raising of any biotype to new species status, the fact remains that $B$. tabaci biotypes A and B are not the same genetically. 
Table III - AMOVA of 109 Bemisia biotype B individuals collected in 12 populations in Brazil.

\begin{tabular}{lcccc}
\hline Source of variation & Degrees of freedom & Sum of squares & Variance components & \% of variation \\
\hline $\begin{array}{l}\text { Between host crops } \\
\text { Within host crops }\end{array}$ & 6 & 51.48 & 0.33 & 22.73 \\
$\quad$ Between populations & 6 & & & 0.00293 \\
$\quad$ Within populations & 101 & 21.45 & 0.30 & 20.56 \\
\hline
\end{tabular}

Recent phylogenetic studies using more effective markers, such as mitochondrial DNA (Frohlich et al., 1999; Kirk et al., 2000) and ribosomal DNA markers (De Barro et al., 2000), showed that the renaming of the B biotype to $B$. argentifolii is premature. These studies suggest that the best way to view $B$. tabaci is as a complex containing geographically distinct populations that exhibit variation across a number of traits. More studies are necessary concerning molecular sequences (mitochondrial and nuclear genomes), host range phenotypes and mating compatibility among biotypes and sub-groups of $B$. tabaci to elucidate this controversy.

\section{Acknowledgements}

This research was supported by Programa de Apoio e Desenvolvimento da Fruticultura do Nordeste (PADFIN) / CNPq.

We are grateful to Dr. Peter W. Inglis for reviewing the manuscript.

\section{References}

Aljanabi SM, Loiácono MS, Lourenço RT, Borges M and Tigano MS (1998) RAPD analysis revealing polymorphism in egg parasitoids of soybean stink bugs (Hemiptera: Pentatomidae). An. Soc. Entomol. Brasil 27:345-352.

Anthony NN, Brown JK, Markham PG and French-Constant RH (1995) Molecular analysis of cyclodiene resistance-associated mutations among populations of sweetpotato whitefly Bemisia tabaci. Pestic. Biochem. Physiol. 51:220-228.

Bellows TSJ, Perring TM, Gill RJ and Hendrick DH (1994) Description of a species of Bemisia (Homoptera: Aleyrodidade). Ann. Entomol. Soc. Amer. 87:195-206.

Bondar G (1929) Aleyrodidos do Brasil (2 ${ }^{a}$ contribuição). Boletim do Laboratório de Patologia Vegetal do Estado da Bahia (Salvador) 5:1-17.

Costa AS, Oliveira AR and Silva DM (1977) Transmissão mecânica do mosaico dourado do tomateiro. Summa Phytopathol. 3:194-200.

Costa HS, Johnson MW, Ullman DE, Omer AD and Tabashnik BE (1993) Sweetpotato whitefly (Homoptera: Aleyrodidae) analysis of biotypes and distribution in Hawaii. Environ. Entom. 22:16-20.

De Barro PJ (1995) Bemisia tabaci biotype B: a review of its biology, distribution and control. CSIRO Division of Entomology Technical Paper 36 ( $2^{\text {nd }}$ edition $), 58 \mathrm{pp}$.

De Barro PJ and Driver F (1997) Use of RAPD PCR to distinguish the $\mathrm{B}$ biotype from other biotypes of Bemisia tabaci
(Gennadius) (Hemiptera: Aleyrodidae). Aust. J. Entomol. 36:149-152.

De Barro PJ, Drive F, Treman JW and Curran J (2000) Phylogenetic relationship of world populations of Bemisia tabaci (Gennadius) using ribosomal ITS1. Mol. Phylog. Evol. 16:29-36.

Drost YC, Lenteren JC Van and Roermund, HJW van (1998) Life history parameters of different biotypes of Bemisia tabaci (Hemiptera: Aleyrodidae) in relation to temperature and host plant: a selective review. Bull. Entomol. Res. 88:219-229.

Excoffier L, Smouse P and Quattro J (1992) Analysis of molecular variance inferred from metric distances among DNA haplotypes: Application to human mitochondrial DNA restriction data. Genetics 131:479-491.

Franzmann BA and Lea DR (2000) Silverleaf whitefly in cotton the Queensland situation 98/99-99/00. Proc. $10^{\text {th }}$ Austr. Cotton Conf.

Frohlich DR, Torrez-Jerez I, Bedford ID, Markham PG and Brown JK (1999) A phylogeographical analysis of the Bemisia tabaci species complex based on mitochondrial DNA markers. Mol. Ecol. 8:1683-1691.

Gawel NJ and Bartlett AC (1993) Characterization of differences between whiteflies using RAPD-PCR. Insect Mol. Biol. 2:33-38.

Guirao P, Beitia F, and Cenis JL (1997) Biotype determination of Spanish populations of Bemisia tabaci (Hemiptera: Aleyrodidae). Bull. Entomol. Res. 87:587-593.

Kirk AA, Lacey LA, Brown JK, Ciomperlik MA, Goolsby JA, Vacek DC, Wendel LE and Napompeth B (2000) Variation in the Bemisia tabaci s. 1. species complex (Hemiptera: Aleyrodidae) and its natural enemies leading to successful biological control of Bemisia biotype B in the USA. Bull. Entomol. Res. 90:317-327.

Lima LHC, Návia D, Inglis PW and Oliveira MRV (2000) Survey of Bemisia tabaci (Gennadius) (Hemiptera: Aleyrodidae) biotypes in Brazil using RAPD markers. Genet. Mol. Biol. 23:1-5.

Liu HY, Cohen S and Duffus JE (1992) The use of isoenzyme patterns to distinguish sweetpotato whitefly biotypes. Phytoparasitica 20:187-194.

Lourenção AL and Nagai H (1994) Surtos populacionais de Bemisia tabaci no Estado de São Paulo. Bragantia 53:53-59.

Martinez SS, Carvalho AOR, Vieira LG, Nunes LM and Bianchini A (2000) Identification, geographical distribution and host plants of Bemisia tabaci (Genn.) biotypes (Homoptera: Aleyrodidae) in the state of Paraná, Brazil. An. Soc. Entomol. Brasil 29:597-603.

Moya A, Guirao P, Cifuentes D, Beitia F and Cenis JL (2001) Genetic diversity Genetic diversity of Iberian populations of Bemisia tabaci (Hemiptera: Aleyrodidae) based on random 
amplified polymorphic DNA-polymerase chain reaction. Mol. Ecol. 10:891-897.

Oliveira MRV and Faria MR (2000) Mosca branca do complexo Bemisia tabaci (Gennadius) (Hemiptera, Aleyrodidae): bioecologia e medidas de controle. Brasília: Embrapa Recursos Genéticos e Biotecnologia. 111 pp. (Embrapa Recursos Genéticos e Biotecnologia. Documentos, 48).

Perring TM, Cooper AD and Kazmer DJ (1992) Identification of the poinsettia strain of Bemisia tabaci (Homoptera: Aleyrodidae) on broccoli by electrophoresis. J. Econ. Entomol., 85:1278-1284.

Perring TM, Cooper AD, Rodriguez RJ, Farrar CA and Bellows TSJ (1993) Identification of a whitefly species by genomic and behavioral studies. Science 259:74-77.

Perring TM (1995) Biological differences of two species of Bemisia that contribute to adaptative advantage. In: Gerling D and Mayer RT (eds) Bemisia: Taxonomy, Biology, Damage, Control and Management. Intercept, Andover, UK. 702 pp.
Rohlf FJ (1993) NTSYS-pc, Numerical taxonomy and multivariate analysis system, v. 1.80. Applied Biostatistics Inc., NY.

Secker AE, Bedford IA, Markham PG and William MEC (1998) Squash, a reliable field indicator for the presence of B biotype of tobacco whitefly, Bemisia tabaci. Brighton Crop Protection Conference: Pests and Diseases 3:837-842.

Schneider S, Kueffer JM, Roessli D and Excoffier L (1997) Arlequim version 1.1: A software for population genetic data analysis. Genetics and Biometry Laboratory, University of Geneva, Switzerland.

Sneath PA and Sokal RR (1973) Numerical Taxonomy. Freeman, San Francisco, 573 pp.

Williams MC, Bedford ID, Kelly A and Markham PG (1996) Bemisia tabaci: Potential infestation and virus transmission within the ornamental plant industry. Brighton Crop Protection Conference: Pests and Diseases 2B:63-68.

Wool D, Gerling D, Bellotti AC and Morales FJ (1993) Esterase electrophoretic variation in Bemisia tabaci (Gennadius) (Hem., Aleyrodidae) among host plants and localities in Israel. J. Appl. Entomol. 115:185-96. 